\title{
p53 Mutation at Serine 249 and Its Gain of Function Are Highly Related to Hepatocellular Carcinoma after Smoking Exposure
}

\author{
Huai Wang ${ }^{a, b} \quad$ Lu Chen $^{c} \quad$ Tong Zhou ${ }^{a, b} \quad$ Zhongwei Zhanga,b Canwei Zeng ${ }^{c}$ \\ aSchool of Public Health, Nanchang University, Nanchang, PR China; ${ }^{b}$ Jiangxi Provincial Key Laboratory of \\ Preventive Medicine, Nanchang University, Nanchang, PR China; ' Wuhan Taisheng Biological Technology Co., Ltd. \\ Wuhan, PR China
}

\section{Keywords}

Tobacco smoking · Hepatocellular carcinoma • Mutant p53 · Serine 249

\begin{abstract}
Background: It has been convincingly suggested that a close correlation exists between the incidence of hepatocellular carcinoma (HCC) and cigarette smoking. However, the underlying effect of smoking on HCC is not clear. Methods: A binary unconditional logistic regression was used for the data on a total of 300 cases and 612 controls. The approach of functional analysis of separated alleles in yeast and direct sequencing of TP53 mutations were applied to analyze the p53 status in the HCC group. The relationship between p53 mutation at serine 249 (p53-RS) and smoking was assessed. Quantitative reverse transcription PCR was employed for the evaluation to transcriptional activity of p53 and p53-RS. Results: Smoking was linked to the risk of HCC with an increased dose-response effect. Moreover, among subjects who did not drink, the risks of HCC were significantly increased for smokers between HCC and controls. Besides, there was an increase in the number of HCC in smokers compared to nonsmokers after exclusion of HBV and/or HCV infection. Also, a significant difference was observed in the incidence of p53-RS between smokers and nonsmokers the HCC group. Furthermore, the p53-RS transcriptional activity
\end{abstract}

karger@karger.com www.karger.com/phg

Karger $\stackrel{\text { ' }}{5}$

GOPEN ACCESS
(C) 2021 The Author(s)

Published by S. Karger AG, Basel

This is an Open Access article licensed under the Creative Commons Attribution-NonCommercial-4.0 International License (CC BY-NC) (http://www.karger.com/Services/OpenAccessLicense), applicable to the online version of the article only. Usage and distribution for commercial purposes requires written permission. was significantly increased in tumor tissues. Conclusions: It strongly demonstrated that tobacco smoking is positively and independently associated with HCC, which may be attributed to p53-RS and its gain of function.

(C) 2021 The Author(s).

Published by S. Karger AG, Basel

\section{Background}

Hepatocellular carcinoma (HCC) accounts for 90\% of primary liver cancer, which is the fourth most common cause of cancer-related deaths worldwide [1]. HCC causes a heavy disease burden and is the leading cause of cancer-related deaths in many parts of the world. It is estimated that HCC is the fourth most common cause of cancer-related deaths worldwide [2]. Even though liver cancer is not one of the most frequently occurring cancers, its high mortality (overall mortality to incidence rate, 0.95 ) and short survival (5-year survival rate is only 6.9\%) cause a serious global health burden [3]. Multiple risk factors leading to HCC have been well-identified, including chronic hepatitis $\mathrm{B}$ virus (HBV) and/or hepatitis C virus (HCV) infections, carcinogen exposure (e.g., aflatoxin B1 and AFB1), excessive alcohol consumption, and multiple genetic factors $[4,5]$.

Chronic HBV and HCV infections are the most important causes of liver cancer, accounting for $80 \%$ of global
Correspondence to:

Huai Wang,wonghuai@ hotmail.com 
HCC cases [6]. Chronic HBV infection is a major cause of HCC in East Asia and most African countries, with the exception of North Africa, where HCV prevalence is highest $[7,8]$. HBV infections are usually obtained vertically from mothers to children in China and other parts of Asia, while sibling transmission is more common in Africa [9]. Overall, the annual incidence of HCC in patients with cirrhosis caused by chronic $\mathrm{HBV}$ or $\mathrm{HCV}$ infection is $2-5 \%$ [10].

Aflatoxins are difuranocoumarin derivatives of Aspergillus aflatoxin and $A$. parasiticus. Fungal contamination occurs both during crop growth and due to the improper storage. High levels of exposure to fungal toxin are widely distributed in sub-Saharan Africa and the Asia-Pacific region. AFB1 is an aflatoxin most often found in contaminated human foodstuffs and is the most potent hepatocarcinogen [11]. One study confirmed the effectiveness of preventing post-harvest contamination through simple interventions, such as drying crops on cloth, rather than soil; hand sorting to remove moldy crops; and better storage practices [12].

Heavy drinking ( $>80 \mathrm{~g} /$ day) for $>10$ years increases the risk of HCC by approximately 5 times [13]. The annual incidence of HCC in patients with alcoholic cirrhosis is $1-2 \%$ [14]. Alcohol consumption and viral hepatitis have synergistic effects on HCC $[15,16]$. Alcoholic cirrhosis is the second most common risk factor for liver cancer in the USA and Europe [17]. A meta-analysis of 19 studies ( $n=$ 5,650 ) by the World Cancer Research Fund found a statistically significant increased risk of $4 \%$ per $10 \mathrm{~g}$ alcohol intake per day, with odds ratios (ORs) of 1.04 and $95 \%$ and confidence intervals (CIs) 1.02-1.06, respectively [18].

The IARC concluded that there was sufficient evidence that tobacco smoking caused liver cancer in 2004 [19]. Also, a meta-analysis estimated that there was a 1.5fold increased risk of HCC among current smokers, a risk similar to that imposed by obesity [20]. Moreover, it was confirmed that cigarette smoking was a risk factor for $\mathrm{HCC}$, regardless of HCV infection status [21]. However, HCC only develops in a small part of the exposed population, which means that genetic factors may contribute to the carcinogenic mechanism.

Indeed, like other cancers, HCC could be considered an acquired genetic disorder defined by an accumulation of somatic genetic alterations in tumor hepatocytes [22]. Following several technological revolutions, a lot of recent pioneering studies have refined the knowledge of the mutational landscape and the related signaling pathway involved in liver carcinogenesis, decoding the whole sequence of an individual or of tumor genomes in a few days that can explore $>20,000$ coding genes [23-25]. The tumor suppressor protein $\mathrm{p} 53$ acts as a transcription factor by regulating the expression of genes involved in various processes, including DNA repair, cell cycle arrest, and apoptotic cell death [26-28]. Thus, p53 plays multiple, coordinated antiproliferative roles in response to many different types of stress stimuli. The p 53 gene is the most frequently mutated gene in human cancer [29]. Interestingly, p53 mutations in serine 249 (p53-RS) are highly associated with HCC, which is often diagnosed in patients with high exposure to AFB1 and/or infected with HBV [30,31]. To date, p53-RS is the only hot spot mutant that has been identified among $30 \%$ of HCC patients that harbor p53 mutations [32-34].

Nicotine is the more abundant component in cigarette smoking, which is first metabolized in liver and increases the risk of developing HCC. Our previous study showed that nicotine could collaborate to HCC promotion for smokers due to gain of function (GOF) of p53-RS [35]. Also, it showed that the expression of Nat2 is significantly downregulated in HCC patients, implicating poor metabolism of exogenous and endogenous compounds in HCC [36]. Besides, enrichment analyses indicated that the differentially expressed genes between HCC and normal samples were significantly enriched in metabolismassociated pathways, and hub genes and module 1 were highly associated with the cell cycle pathway [37]. In addition, cigarette smoke also induces oxidative stress by stimulating NADPH oxidase and decreasing antioxidant defenses, leading to reactive oxygen species generation and lipid peroxidation, which could induce hepatic injury and subsequent activation of resident hepatic stellate cells, a major fibrogenic cell type [38, 39].

In the present study, we also sought to understand more fully the critical determinants for the carcinogenic activity of tobacco smoking. First, it also showed a significant dose-response and positive association between smoking and HCC risk. Moreover, there was a statistically significant correlation between p53-RS and smoking, and it was further demonstrated that the increase in liver cancer cases among smokers may be partly due to p53-RS and its GOF.

\section{Methods}

\section{Study Population}

The study had a hospital-based case-control design. Between June 2013 and December 2018, we enrolled 300 cases of HCC, and those who were diagnosed within 1 year prior to admission were also regarded as eligible. HCC were diagnosed on the basis of 
pathology, cytology, or an elevated $\alpha$-fetoprotein level (400 ng/ $\mathrm{mL}$ ) combined with positive findings in at least 2 diagnostic imaging examinations, including angiography, sonography, and computerized tomography scans. Their control subjects, considered hospital controls, were hospitalized for reasons other than liver disease, such as chronic hepatitis or hepatic cirrhosis, as well as neoplasms and tobacco- or alcohol-related disease, and were genetically unrelated family member (i.e., spouses and in-laws) and matched for age (within the same 5-year age class), gender, residence (prefecture), and time of hospitalization (with 2 months after a case interview).

\section{Laboratory Testing}

Blood samples from HCC cases $(n=300)$ and hospital controls ( $n=612)$ were tested for HBV and HCV. Hepatitis-B surface antigen (HBsAg) was detected by an immunoassay (Bio-Rad Laboratories, Redmond, WA, USA). Antibody to hepatitis $\mathrm{C}$ virus (anti-HCV) was determined by a second-generation enzyme immunoassay (Bio-Rad Laboratories, Redmond, WA, USA). Results were interpreted according to the manufacturer's instructions. Positive results prompted repeated confirmatory enzyme-linked immunosorbent assay testing. Technicians who performed the blood tests were blinded to the identity and disease status of participants. Peripheral blood samples were taken from patients and controls, and blood specimens, including white blood cells and serum, were frozen at $-80^{\circ} \mathrm{C}$ until analysis.

\section{Questionnaire}

All HCC patients and hospital controls were interviewed in the hospital. Personal general information including age, gender, height, and alcohol and smoking status was elicited during questionnaire-based interviews. Also, questionnaires were structured to obtain information about participants' body weight before cancer diagnosis (HCC patients) or before recruitment (hospital controls). The body mass index (BMI) was estimated from the participants' weight $(\mathrm{kg})$ and height $(\mathrm{m})$. Alcohol drinkers were defined as individuals who drank any alcoholic beverage on a monthly basis or more often. Those who had stopped smoking $>3$ years before the onset of HCC were considered former smokers. Those who had stopped smoking within the 3 years prior to disease diagnosis were considered current smokers. Besides, former smokers were classified on the basis of the daily number of cigarettes smoked in the past ( $<2$ and $\geq 2$ packs/day, 20 cigarettes per pack), while the current ones were classified in line with the daily number of cigarettes smoked before the onset of HCC or a corresponding date in the controls ( $<2$ and $\geq 2$ packs/day, 20 cigarettes per pack).

\section{p53 Determination}

All patients underwent complete resection of liver tumor. In each case, fragments of the tumor and corresponding normal tissue were obtained and partly immediately snap frozen in liquid nitrogen and stored at $-80^{\circ} \mathrm{C}$ until further testing for p53 transcriptional activity to prevent degradation of RNA. The remaining tumor materials were fixed in $10 \%$ buffered formalin, embedded in paraffin, sectioned, and stained with hematoxylin-eosin for pathologic evaluation. The pathologic classification, including tumor grade and stage, was assessed according to the World Health Organization system and TNM classifications [40], respectively.

p53 gene functional status was determined by the functional analysis of separated alleles in yeast (FASAY) method described previously [41]. In brief, according to the manufacturer's instructions, total RNA was extracted from tumor materials using the RNeasy mini kit, and then RNA samples were reverse transcribed at $37^{\circ} \mathrm{C}$. The p53 cDNA was amplified using PCR with the following primers: $5^{\prime}$-CCT TGC CGT CCC AAG CAA TGG ATG AT-3' for P3 and $5^{\prime}$-ACC CTT TTT GGA CTT CAG GTG GCT GGA GT-3' for P4 (Invitrogen, Carlsbad, CA, USA) and Pfu DNA Polymerase (Stratagene). Crude polymerase chain reaction product and linearized p53 expression vector were co-transfected into the yeast reporter strain yIG397. Transformed yeast cells were plated on a minimal medium without leucine and with a low amount of adenine $(5 \mu \mathrm{g} / \mathrm{mL})$, followed by incubation for $2-3$ days at $35^{\circ} \mathrm{C}$ and then for 2-3 days at room temperature. Experiments were repeated at least twice, and the average percentage of red colonies was determined. p53 status was considered mutated on the basis of the following criteria from Lehmann-Che et al. [42]: (a) $>10 \%$ of the yeast colonies were red, (b) defects in the $5^{\prime}$ or $3^{\prime}$ section of the gene can be identified by the analysis of the split versions of the test, and (c) sequence analysis of mutant yeast colonies can identify clear genetic defects. The existence of $>4$ clonal mutations within sequenced yeast colonies was the criterion for the final definition of mutation.

\section{Direct Sequencing of TP53 Mutations}

Genomic DNA was extracted from tumor materials, and the procedure was performed according to the manufacturer's instructions. DNA was amplified by PCR to generate 110-bp product encompassing codon 249 located at exon 7 of TP53. The primers used were P1 5'-GTT GGC TCT GAC TGT ACC AC- $3^{\prime}$ and P2 5'-CTG GAG TCT TCC AGT GTG AT- ${ }^{\prime}$. The PCR products were sequenced using the Sanger sequencing method according to the protocol used at the International Agency for Research on Cancer (IARC) (https://p53.iarc.fr/ Download/TP53_SangerSequencing_IARC.pdf). We sequenced amplicons on an ABI 3730 DNA Analyzer (Thermo Fisher Scientific Corporation, Waltham, MA, USA). Sanger sequences were analyzed with Sequencher 5.1 software (Gene Codes Corporation, Ann Arbor, MI, USA).

\section{RNA Isolation and Quantitative Reverse-Transcription PCR Analysis}

Following the manufacturer's instructions, an RNA kit was used for the extraction of samples from freshly frozen tumor tissue and normal nontumor mucosa (RNeasy Lipid Tissue Qiagen kit, 74804; Qiagen, Valencia, CA, USA). Quantitative reverse-transcription PCR (qRT-PCR) was done using IQ SYBR green (Bio-Rad, Hercules, CA, USA) and GAPDH as the reference gene. The relative expression of mRNA was determined by the comparative $\mathrm{Ct}$ method ( $\Delta \Delta$ Ct method). Each sample was analyzed in triplicate by qRT-PCR. The designed primer sequences were as follows: $5^{\prime}-$ GAG ACA CCA CTG GAG GGT GAC TTC G-3' and $5^{\prime}$-GGG CAA ACA ACA GAT GGC TGG CAA C-3' for human p21; $5^{\prime}$ GAG GAT GAT TGC CGC CGT GGA CA- $3^{\prime}$ and $5^{\prime}$-GGT GGG GGA GGA GGC TTG AGG-3' for human Bax; $5^{\prime}$-AAA ACT AGT CGA CGA TGC CCC TCA ACG TTA GC- $3^{\prime}$ and $5^{\prime}$-AAA AAG CTT GGT CGG CCG TGG AGA AGC TCC C-3' for human cMyc; 5'-CGC GCA TGC AAG TGG CAT ATA ACT- $3^{\prime}$ and $5^{\prime}$ AAG CTC GAA CCA CTG TGA CAT CCT- $3^{\prime}$ for human STAT1; $5^{\prime}$-GAG TCA ACG GAT TTG GTC GT- $3^{\prime}$; and 5'-GAC AAG CTT CCC GTT CTC AG-3' for human GAPDH. 
Table 1. Gender-specific distribution of HCC cases and hospital controls by smoking habit, with OR and 95\% CI

\begin{tabular}{|c|c|c|c|c|c|}
\hline & \multicolumn{2}{|c|}{ HCC cases $(n=300)$} & \multicolumn{2}{|c|}{ Hospital controls $(n=612)$} & \multirow[t]{2}{*}{ OR $(95 \% \mathrm{CI})$} \\
\hline & $\begin{array}{l}\text { men } \\
(n=198)\end{array}$ & $\begin{array}{l}\text { women } \\
(n=102)\end{array}$ & $\begin{array}{l}\text { men } \\
(n=468)\end{array}$ & $\begin{array}{l}\text { women } \\
(n=144)\end{array}$ & \\
\hline \multicolumn{6}{|l|}{ Smoking status, packs/day } \\
\hline Never smoker, $n(\%)$ & $54(27.27)$ & $66(64.70)$ & $288(61.54)$ & $132(91.67)$ & 1.000 \\
\hline Current smoker, $n(\%)$ & $90(45.45)$ & $24(23.53)$ & $108(23.08)$ & $6(4.17)$ & $3.500(2.518-4.866)$ \\
\hline$<2$ & $66(33.33)$ & $18(17.65)$ & $84(17.95)$ & $6(4.17)$ & $3.267(2.279-4.682)$ \\
\hline$\geq 2$ & $24(12.12)$ & $6(5.88)$ & $24(5.13)$ & $0(0.00)$ & $4.375(2.465-7.766)$ \\
\hline Former smoker, $n(\%)$ & $54(27.27)$ & $12(11.76)$ & $72(15.39)$ & $6(4.17)$ & $2.962(2.014-4.355)$ \\
\hline$<2$ & $36(18.18)$ & $6(5.88)$ & $54(11.54)$ & $6(4.17)$ & $2.450(1.572-3.817)$ \\
\hline$\geq 2$ & $18(9.09)$ & $6(5.88)$ & $18(3.85)$ & $0(0.00)$ & $4.667(2.451-8.885)$ \\
\hline
\end{tabular}

HCC, hepatocellular carcinoma; OR, odds ratio; CI, confidence interval.

\section{Statistical Analysis}

All statistical analyses were performed using SPSS for Windows (version 25.0, Chicago, IL, USA). Differences in the distributions of demographic characteristics between HCC cases and hospital controls were evaluated using the $\chi^{2}$ test (qualitative data) and unpaired two-tailed Student's $t$ test (quantitative data). Also, hierarchical analysis and unconditional logistic regression model were used to generate OR with 95\% CI for HCC risk as relative risk estimation [43]. Because it is impossible for some HCC cases to match individual, it is necessary to carry out the unconditional logistic regression model analysis, instead of the conditional, adjusting for the matching factors. The likelihood ratio test is the difference between maximum logarithmic and likelihood statistics, and it is used to evaluate the significance of additional covariates in the model [43]. All $p$ values quoted were two-sided, and significant differences were considered at a $p<0.05$.

\section{Results}

\section{Tobacco Smoking Is Positively and Independently}

\section{Associated with HCC}

Online suppl. Table 1 (for all online suppl. material, see www.karger.com/doi/10.1159/000516598) shows the distribution of study subjects by demographic characteristics, serologic evidence of chronic infection with HBV, infection with HCV, smoking status, and alcohol consumption. HCC cases and hospital controls were similarly distributed by age, gender, and body mass index. There were, as expected, significant differences $(p<0.05)$ in gender status and prevalence of $\mathrm{HBV}$ and $\mathrm{HCV}$ infection markers because these are the main reasons for HCC. Also, interestingly, it was found that smokers were significantly more likely to be associated with HCC than nonsmokers $\left(\chi^{2}=67.131, p=0.000\right)$ and smoking was more common among cases than among controls.
We further examined the cigarette smoking-HCC association. Table 1 shows the distribution of HCC cases and hospital controls by smoking habits. The distributions were gender-specific on account of the expected differences in the prevalence of these activities by gender. Smokers were significantly associated with HCC. The corresponding estimates were $3.500(95 \% \mathrm{CI}=2.518-4.866)$ and 2.962 (95\% CI $=2.014-4.355)$ for current smokers and former smokers, respectively. In terms of dose, there appeared to be a dose-response relationship between HCC and quantity smoked with adjusted OR estimates of 3.267 and 4.375 for smoking $<2$ and $\geq 2$ packs per day for current smokers, respectively. Likewise, significant OR variation was found when considering only a group of subjects among former smokers, the OR for $<2$ and $\geq 2$ packs per day being 2.450 $(95 \% \mathrm{CI}=1.572-3.817)$ and $4.667(95 \% \mathrm{CI}=2.451-8.885)$, respectively. Altogether, it demonstrated that smoking was associated with an increased risk of HCC according to the adjustment of age and gender, but mutual confounding precludes alcohol intake and valid etiological inferences.

We also further explored the independent and joint effects of smoking and alcohol consumption on risk of HCC with stratification by age, gender, and body mass index. The distribution of cases and controls by smoking status and the adjusted risks of HCC in relation to smoking status by alcohol intake are shown in Table 2. Compared with never smokers, current and former smokers both had an increased HCC risk of significance. Interestingly, subjects who consumed alcohol had a significantly increased risk. Moreover, stratification revealed that nondrinkers had a significant dose-response increase in HCC disease risk. The overall risks of HCC were significantly increased among current smokers smoking $<2$ packs per day $(\mathrm{OR}=2.800,95 \% \mathrm{CI}=1.933-4.055)$ 


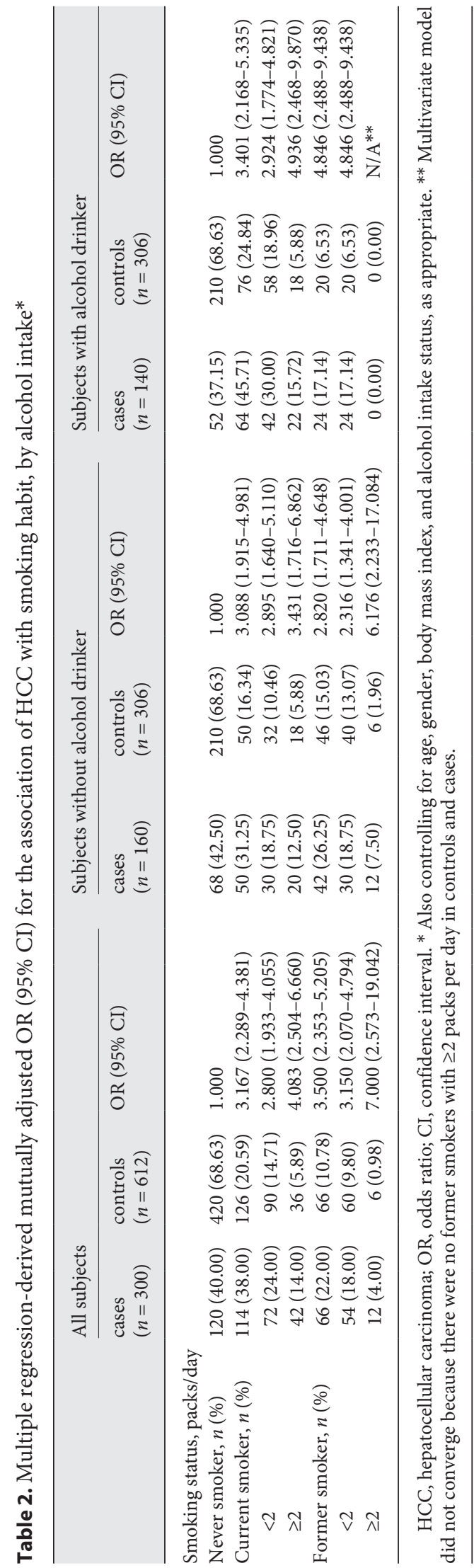

Incidence of Hepatocellular Carcinoma and Cigarette Smoking between HCC patients and controls, and these risks were of similar magnitude among nondrinkers, with an estimated effect much higher than that for never smokers $(\mathrm{OR}=2.895$, $95 \% \mathrm{CI}=1.640-5.110)$. Compared with current smokers, former smokers had significant increases in the risk of HCC overall $(<2$ packs per day, $\mathrm{OR}=3.150,95 \% \mathrm{CI}=2.070$ $4.794)$ and by subtype of nonalcohol drinking $(<2$ packs per day, $\mathrm{OR}=2.316,95 \% \mathrm{CI}=1.341-4.001$ ).

Table 3 shows the multiple regression-derived, mutually adjusted OR and 95\% CI for the association of HCC with consumption patterns of cigarettes. Because the latency of a possible smoking associated with HCC had not yet been determined, we chose to study the impact of daily smoking, regardless of the current or previous smoking status. Data were shown for all subjects and also were stratified according to serological evidence of HBV and/ or HCV infection. Compared with nonsmokers, the relative risk of HCC for smokers was estimated to be 3.281 (95\% CI $=2.462-4.373)$. Risk was also higher among HBsAg and anti-HCV negative participants, among whom the relative risk of HCC was 2.145 (95\% CI $=1.415-$ 3.251) compared with nonsmokers. Also, it indicated a dose-response relationship with the number of cigarettes smoked per day between smoking and HCC overall risk ( $<2$ packs per day, $\mathrm{OR}=2.940,95 \% \mathrm{CI}=2.152-4.016 ; \geq 2$ packs per day, $\mathrm{OR}=4.500,95 \% \mathrm{CI}=2.865-7.067)$, which was positively correlated. Besides, as far as smoking was concerned, the association with HCC risk was stronger in individuals without chronic viral infection than those nonsmokers $(<2$ packs per day, $\mathrm{OR}=1.727,95 \% \mathrm{CI}=1.090$ 2.738 ; $\geq 2$ packs per day, $\mathrm{OR}=3.855,95 \% \mathrm{CI}=2.021-7.351$ ). These data convincingly suggested a super-multiplicative, interactive effect of smoking on the development of HCC in a statistically significant, dose-dependent manner.

\section{p53-RS and Its GOF Are Associated with an Increased Risk of HCC among Cigarette Smokers}

p53 gene mutation is one of the most common genetic changes in human cancer. The advantage of these mutations (95\%) is missense mutations, which are mainly located in the DNA-binding domain (amino acids 94292), with hot spots at codons R175, G245, R248, R249, R273, and R282 [44, 45]. FASAY has proved to reach the highest sensitivity and specificity of p53 mutation detection $[46,47]$, due to the fact that a larger region of the p53 gene in exon 4-10 was tested. Then mutations can be detected in a large number of normal tissues because there are hundreds of clones examined in each sample, and the simple red versus white readout means that mutations are not overlooked easily [48]. In addition, FASAY can exclude 


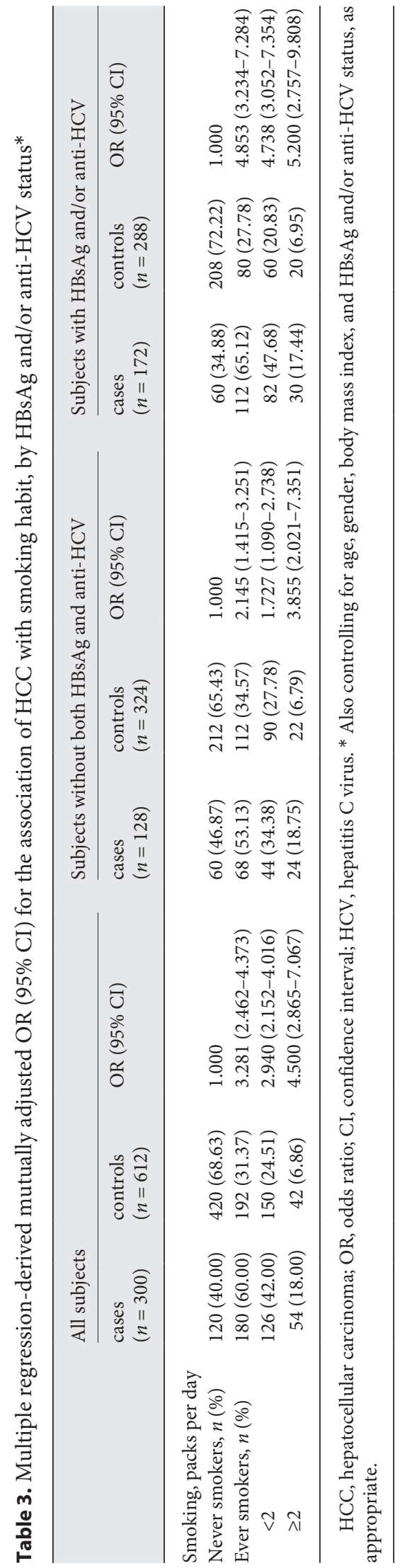

p53 polymorphisms that do not affect their transcriptional activity [49]. To detect the status of p53 in HCC tumors, the tumor mucosa of 300 patients was examined using FASAY (online suppl. Table 2). In total, 228 tumors (76.00\%) were positive (mutant) by FASAY. Besides, analysis of plasmid sequencing from red yeast colony showed that 210 of 228 plasmids were point missense mutations, 6 of 228 was frameshift deletion mutation, 9 of 228 were in-frameshift deletion mutations, and 3 of 228 were splicing mutations (Fig. 1a). Moreover, hot spot mutation p53-RS occurred 126 times in this study, accounting for $55.26 \%$ in total mutations. We further evaluated the relation between tobacco smoking and p53-RS mutation. A striking increase in the risk of p53-RS was observed for smokers (Fig. 1b). Furthermore, these differences in the incidence of p53-RS between smokers and nonsmokers were statistically significant by the $\chi^{2}$ test (56.67 vs. $20.00 \% ; \chi^{2}=38.246, p=0.000$ ). However, there was no difference between the incidence of p53-RS and smoker status $\left(\chi^{2}=2.339, p=0.126\right)$ (online suppl. Table $3)$, as well as the number of cigarettes smoked $\left(\chi^{2}=1.035\right.$, $p=0.309$ ) (online suppl. Table 4). Strikingly, we were also able to detect a p53 mutation on codon 249 with a base exchange from AGG to AGT (p53-RS) for smokers by Sanger sequencing of the PCR-amplified DNA (Fig. 1c). These results suggested that p53-RS mutation might be associated with the response to cigarette smoking. We also sought to determine whether the presence of p53-RS has a measurable effect on the expression of p53 major transcriptional targets (p21 and Bax), as well as p53-RSdependent target genes including c-Myc [50] and STAT1 [51] by using qRT-PCR on mRNA from fresh frozen components. For $\mathrm{p} 21$ and Bax, we found a decreased profile in the p53-RS group compared with the WT p53 group (Fig. 1d, e). More elaborately, when we compared the $\mathrm{p} 21$ expression of the WT p53 group with that of the p53-RS group, the percentage of $\mathrm{p} 21$ reduction in the p53-RS group was higher than that of the WT p53 group in Figure 1d ( 23 vs. $65 \%, p<0.001)$. Similar results were obtained for Bax with higher percentage in the p53-RS group ( 31 vs. $63 \%, p<0.001$ ) (Fig. 1e). However, in contrast to the WT p53 group, we observed an increased expression of c-Myc and STAT1 in the tumors with p53-RS. First, the percentage of c-Myc overexpression in the WT p53 group was $38 \%$, whereas p53-RS increased the percentage to $58 \%$ in the $\mathrm{p} 53$-RS group. The above difference was statistically significant $(p<0.001$, Fig. 1f). Furthermore, p53-RS also markedly promoted the STAT1 expression level $(p<0.001$, Fig. $1 \mathrm{~g})$, with the percentage of its overexpression in the p53-RS group and WT p53 group being 
Fig. 1. Distribution of TP53 and effect of p53-RS mutations on expression of p53 and p53-RS target genes. a Repartition of the TP53 mutations among mutated cases. 210-point missense mutations were observed among 228 mutation cases (92.11\%). Eighteen cases showed 3 other mutations: Six frameshift mutations (2.63\%) along with 9 in-frameshift deletion mutations (3.95\%) and 3 splicing mutations (1.32\%). b Number of HCC in p53-RS and nonp53-RS between smokers and nonsmokers $\left.{ }^{* *} p<0.001\right)$. c Sanger sequencing of genomic DNA from HCC specimens revealed the mutation of $\mathrm{p} 53$ on codon 249 (AGG to AGT) for smokers (arrow indicates the mutation). $\mathbf{d}-\mathbf{g}$ Variation in the expression of Bax and p21, as well as c-Myc and STAT1 in the WT p53 and p53-RS groups of tumors, evaluated by qRT-PCR $\left.{ }^{* *} p<0.001\right)$. d Percentage of tumors that have a decreased, invariant, or increased expression of $\mathrm{p} 21$, respectively. e In the p53-RS group and WT p53 group, the percentage in tumors of Bax expression changes (tumors vs. normal). $\mathbf{f}$ Percentage of tumors with decreased, invariant, or increased cMyc expression in the p53-RS group and WT p53 group. g Compared with normal tissue, the percentage in tumor of STAT1 expression changes in the p53-RS group and WT p53 group, respectively. p53-RS, p53 mutations in serine 249; HCC, hepatocellular carcinoma; qRT-PCR, quantitative reverse transcription PCR.
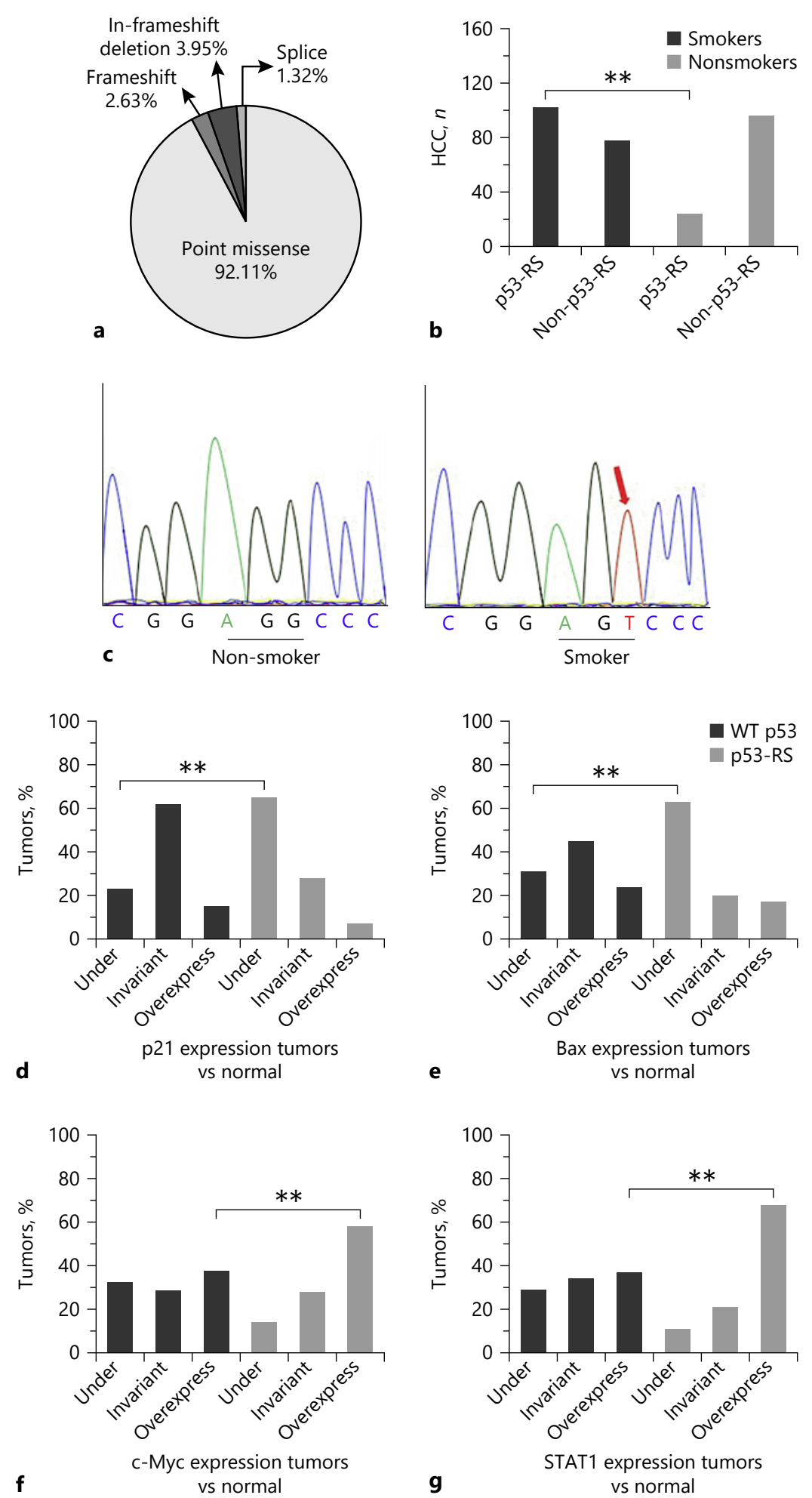
37 and $68 \%$, respectively. Overall, it demonstrated a loss of transcriptional p53 function and p53-RS GOF for tumors.

\section{Discussion}

Whether smoking is a risk factor for HCC is currently controversial. Although an increased risk of HCC is observed in smokers, there are no significant differences [52]. Besides, research studies also report that smoking is a potential risk factor for HCC [19-21]. Smoking increases the risk of liver cancer. Former smokers have a lower risk than current smokers, but both groups have a higher risk than those who never smoked. However, the carcinogenic action of smoking on HCC also needs to be elucidated. Thus, our goal is to carry out a clear examination to find the independent influence of smoking on liver cancer in this study. Also, the purpose of this study is to explore the potential causes of HCC development among smokers, using the p53 yeast assay and the direct sequencing analysis of TP53 mutations.

Indeed, our results also indicated that $\mathrm{HBV}$ and $\mathrm{HCV}$ infection and alcohol consumption increase the risk for liver cancer. This observed association was in agreement with other recent study on this topic [53]. Importantly, it showed that smoking is also an independent risk factor for HCC in our study (Table 1). Moreover, smokers who did not consume alcohol on a daily basis were shown to exhibit at least 2.316-fold increased risk of HCC (current smoker: $<2$ packs per day, $\mathrm{OR}=2.895 ; \geq 2$ packs per day, $\mathrm{OR}=3.431$; former smoker: $<2$ packs per day, $\mathrm{OR}=2.316, \geq 2$ packs per day, $\mathrm{OR}=6.176$, Table 2). Also, we found evidence that smoking is an important cause of HCC in people with nonchronic $\mathrm{HBV}$ or $\mathrm{HCV}$ infections ( $<2$ packs per day, $\mathrm{OR}=1.727 ; \geq 2$ packs per day, $\mathrm{OR}=3.855$, Table 3 ). However, HCC develops in only a few exposed populations, and the complex interactions between many genetic and environmental factors may be the major cause of HCC.

p53 is a well-known tumor suppressor gene whose mutation plays an important role in the pathogenesis of HCC. Moreover, it is suggested that $\mathrm{p} 53-\mathrm{RS}$ mutant protein products may have specific biological effects that promote hepatocyte transformation and/or liver cancer progression, resulting in the selection of cells expressing this mutant during HCC [54]. FASAY can use yeast cell yIG397 to evaluate the functional status of $\mathrm{p} 53$ protein expressed in tumor cells, thereby detecting important functional mutations of p53 as a transcription factor. Also, the assessment of p53 transcriptional activity by FASAY in cancer cells has been demonstrated to be a useful valuable alternative to p53 nuclear overexpression [55]. Furthermore, it is vali- dated that the assay is a rapid, reliable, and effective method in mutagenesis research and can be used to study the mutagenicity on the origin of the codon 249 hot spot of p53 mutation [56]. Remarkably, our studies showed the various types of p53 mutations in HCC using FASAY in the current work and that most of them were p53-RS, accounting for $55.26 \%$ in total mutations (online suppl. Table 2). Moreover, it also demonstrated the striking relation between tobacco smoking and p53-RS (Fig. 1b, $p<0.001$; Fig. 1c). This may be because nicotine in cigarettes for smokers could be converted to carcinogenic nitrosamines, which is called 4-(methylnitrosamino)-1-(3-pyridyl)1-butanone (NNK) in the liver. Then nicotine and NNK could form adducts with DNA, causing gene changes in cells. Some fixed changes can cause DNA replication errors, leading to mutations [57]. However, it was not significantly different when considering the effect of the smoking status and number of cigarettes on incidence of p53-RS (online suppl. Tables 3, 4), and larger sample sizes should lead to more reliable conclusions in future study. Importantly, at the functional level, the effect what we observed was the decrease in expression of $\mathrm{p} 21$ and Bax at the mRNA level in many mutated tumors as a direct consequence of p53-RS, whereas the mRNA levels of the p53RS targets (c-Myc and STAT1) seemed to be increased (Fig. 1d-g). Altogether, it strongly demonstrated that tobacco smoking is a causal factor for HCC development, which was attributed to p53-RS GOF, and this may be partly explained by our previous study that nicotine induces mutant p53 GOF, activating the CDK6-p53-RS-PIN1STAT1 signaling pathway and promoting human normal fetal hepatic cell proliferation in vitro [35]. Besides, there were 78 cases of smokers without p53-RS (78/180) in the HCC group from Figure $1 \mathrm{~b}$, and it showed that other factors may contribute to the occurrence of liver cancer caused by smoking. Also, from the fact that 24 cases with p53-RS (24/120) were diagnosed with HCC for nonsmokers, it demonstrated that many other factors may be associated with p53 mutation, leading to hepatocarcinogenesis. We will further investigate them, which will be reported in our future work. Moreover, because e-cigarettes also contain nicotine, the correlation between e-cigarettes and development of HCC appears to be an interesting study that necessitates in-depth investigation, and results will be reported in due course. Additionally, the detailed mechanism also needs to be explored in the future.

Also, several limitations of this study should be considered. First, our research enrolled the population by convenience sampling, which cannot represent the whole population of China nor the world. Second, variables such as 
alcohol status are not available in the data, which are considered potential risk factors of HCC. Considering that alcohol plays an important role in the development of HCC with a dose-effect relationship [58], consumption of $>3$ drinks per day may be positively associated with HCC incidence [59]. These findings should be followed by a detailed investigation into the effect of light alcohol drinking or smoking to support the association of HCC with smoking habit, especially for those subjects with light alcohol drinking behavior, which will be reported in future. Not only does it offers thorough evidence about whether smoking has an effect similar to what happens in other exposures, such as HBV or/and HCV infection, as well as chronic alcohol abuse, but it provides more powerful information about the independent role of smoking in HCC.

\section{Conclusions}

Our results suggested that tobacco smoking is associated with HCC, independent from other major HCC risk factors, and this dose-response association was positive significantly. Besides, the present investigation indicated that the p53-RS might confer genetic susceptibility that influences HCC development, especially in smoker patients. Based on these findings, it is conceivable that smokers have a high potential for HCC, who should receive clinical monitoring for p53-RS, and even treatment.

\section{Acknowledgements}

We would like to thank all the participants for their contributions to the present study as well as the specialists without whose support the present study would not have been completed. Also, we wish to thank the editor, the associate editor, and the 3 anony- mous reviewers for their helpful comments and suggestions, which have led to an improvement of this article.

\section{Statement of Ethics}

The study protocol was approved by the Local Ethics Committee (Ethical Committee of Wuhan Hannan District People's Hospital with the following reference number: HN-2015-0606). The authors assert that all procedures performed in studies involving human participants were in accordance with the ethical standards of the relevant national and institutional committees on human experimentation and with the Helsinki Declaration of 1975, as well as its later amendment in 2008. Also, written consent was obtained from all participants in the study.

\section{Conflict of Interest Statement}

The authors declare that they have no competing interests.

\section{Funding Sources}

This work was supported by the Program of Natural Science Foundation of Jiangxi Province of China (Nos. 20171BAB215076 and 20181BAB205089) and Research and Development Fund for Young Teachers, Department of Medicine, Nanchang University (No. PY201808).

\section{Author Contributions}

H.W. conceived of the study and participated in its design, contributed to the analysis and interpretation of data, and drafted the manuscript. L.C. contributed to the study design, participated in the data collection, and helped revise the manuscript. TZ contributed to the data sorting and participated in the data collection and quality control of the data. Z.Z. contributed to the data collection and participated in the data sorting. C.Z. was involved in the data collection and analysis. All authors read and approved the final manuscript.

\section{References}

1 Kim E, Viatour P. Hepatocellular carcinoma: old friends and new tricks. Exp Mol Med. 2020;52:1898-907.

2 Global Burden of Disease Cancer Collaboration. Global, regional, and national cancer incidence, mortality, years of life lost, years lived with disability, and disability-adjusted life-years for 32 cancer groups, 1990 to 2015: a systematic analysis for the global burden of disease study. JAMA Oncol. 2017;3:524-48.

3 Ozakyol A. Global epidemiology of hepatocellular carcinoma (HCC epidemiology). J Gastrointest Canc. 2017;48(3):238-40.

4 Llovet JM, Burroughs A, Bruix J. Hepatocellular carcinoma. Lancet. 2003;362:1907-17.
5 Farazi PA, DePinho RA. Hepatocellular carcinoma pathogenesis: from genes to environment. Nat Rev Cancer. 2006;6:674-87.

6 Yang JD, Roberts LR. Hepatocellular carcinoma: a global view. Nat Rev Gastroenterol Hepatol. 2010;7:448-58.

7 Park JW, Chen M, Colombo M, Roberts LR, Schwartz M, Chen PJ, et al. Global patterns of hepatocellular carcinoma management from diagnosis to death: the BRIDGE Study. Liver Int. 2015;35:2155-66.

8 Kew MC. Epidemiology of chronic hepatitis B virus infection, hepatocellular carcinoma, and hepatitis B virus-induced hepatocellular carcinoma. Pathol Biol. 2010;58:273-7.
9 Custer B, Sullivan SD, Hazlet TK, Iloeje U, Veenstra DL, Kowdley KV. Global epidemiology of hepatitis B virus. J Clin Gastroenterol. 2004;38:S158-68.

10 Yang JD, Mohamed HA, Cvinar JL, Gores GJ, Roberts LR, Kim WR. Diabetes mellitus heightens the risk of hepatocellular carcinoma except in patients with hepatitis c cirrhosis. Am J Gastroenterol. 2016;111:1573-80.

11 Wild CP, Gong YY. Mycotoxins and human disease: a largely ignored global health issue. Carcinogenesis. 2010;31:71-82.

12 Sudakin DL. Dietary aflatoxin exposure and chemoprevention of cancer: a clinical review. J Toxicol Clin Toxicol. 2003;41:195-204. 
13 Morgan TR, Mandayam S, Jamal MM. Alcohol and hepatocellular carcinoma. Gastroenterology. 2004; 127:S87-96.

14 Seitz HK, Stickel F. Risk factors and mechanisms of hepatocarcinogenesis with special emphasis on alcohol and oxidative stress. Biol Chem. 2006;387:349-60.

15 Gao B. Interaction of alcohol and hepatitis viral proteins: implication in synergistic effect of alcohol drinking and viral hepatitis on liver injury. Alcohol. 2002;27:69-72.

16 Hassan MM, Hwang LY, Hatten CJ, Swaim M, Li D, Abbruzzese JL, et al. Risk factors for hepatocellular carcinoma: synergism of alcohol with viral hepatitis and diabetes mellitus. Hepatology. 2002;36:1206-13.

17 Park JW, Chen M, Colombo M, Roberts LR, Schwartz M, Chen PJ, et al. Global patterns of hepatocellular carcinoma management from diagnosis to death: the bridge study. Liver Int. 2015;35:2155-66.

18 Yang JD, Hainaut P, Gores GJ, Amadou A, Plymoth A, Roberts LR. A global view of hepatocellular carcinoma: trends, risk, prevention and management. Nat Rev Gastroenterol Hepatol. 2019;16:589-604.

19 IARC Working Group on the Evaluation of Carcinogenic Risks to Humans. Tobacco smoke and involuntary smoking. IARC Monogr Eval Carcinog Risks Hum. 2004;83:1-1438.

20 Lee YC, Cohet C, Yang YC, Stayner L, Hashibe M, Straif K. Meta-analysis of epidemiologic studies on cigarette smoking and liver cancer. Int J Epidemiol. 2009;38:1497511.

21 Shen Y, Risch H, Lu L, Ma X, Irwin ML, Lim JK, et al. Risk factors for hepatocellular carcinoma (HCC) in the northeast of the United States: results of a case-control study. Cancer Causes Control. 2020;31: 321-32.

22 Vogelstein B, Papadopoulos N, Velculescu VE, Zhou S, Diaz LA Jr, Kinzler KW. Cancer genome landscapes. Science. 2013;339:154658.

23 Guichard C, Amaddeo G, Imbeaud S, Ladeiro $\mathrm{Y}$, Pelletier L, Maad IB, et al. Integrated analysis of somatic mutations and focal copy-number changes identifies key genes and pathways in hepatocellular carcinoma. Nat Genet. 2012;44: 694-8.

24 Fujimoto A, Totoki Y, Abe T, Boroevich KA, Hosoda F, Nguyen HH, et al. Whole-genome sequencing of liver cancers identifies etiological influences on mutation patterns and recurrent mutations in chromatin regulators. Nat Genet. 2012;44:760-4.

25 Huang J, Deng Q, Wang Q, Li KY, Dai JH, Li $\mathrm{N}$, et al. Exome sequencing of hepatitis B virus-associated hepatocellular carcinoma. Nat Genet. 2012;44:1117-21.

26 Oren M. Decision making by p53: life, death and cancer. Cell Death Differ. 2003;10:43142.

27 Vogelstein B, Lane D, Levine AJ. Surfing the p53 network. Nature. 2000;408:30710.
28 Vousden KH, Lu X. Live or let die: the cell's response to p53. Nat Rev Cancer. 2002;2:594-604.

29 Hernandez-Boussard T, Rodriguez-Tome P, Montesano R, Hainaut P. IARC p53 mutation database: a relational database to compile and analyze p53 mutations in human tumors and cell lines. International agency for research on cancer. Hum Mutat. 1999; 14:1-8.

30 Villar S, Ortiz-Cuaran S, Abedi-Ardekani B, Gouas D, Nogueira da Costa A, Plymoth A, et al. Aflatoxin-induced TP53 R249S mutation in hepatocellular carcinoma in Thailand: association with tumors developing in the absence of liver cirrhosis. PLoS One. 2012;7: e37707.

31 Gouas DA, Villar S, Ortiz-Cuaran S, Legros P, Ferro G, Kirk GD, et al. TP53 R249S mutation, genetic variations in HBX and risk of hepatocellular carcinoma in The Gambia. Carcinogenesis. 2012;33:1219-24.

32 Hsu IC, Metcalf RA, Sun T, Welsh JA, Wang NJ, Harris CC. Mutational hotspot in the p53 gene in human hepatocellular carcinomas. Nature. 1991;350:427-8.

33 Hussain SP, Schwank J, Staib F, Wang XW, Harris CC. TP53 mutations and hepatocellular carcinoma: insights into the etiology and pathogenesis of liver cancer. Oncogene. 2007; 26:2166-76.

34 Qi LN, Bai T, Chen ZS, Wu FX, Chen YY, De Xiang B, et al. The p53 mutation spectrum in hepatocellular carcinoma from Guangxi, China: role of chronic hepatitis B virus infection and aflatoxin B1 exposure. Liver Int. 2015;35: 999-1009.

35 Wang H, Chen L, Zhou T, Zhang Z, Zeng C. Nicotine promotes WRL68 cells proliferation due to the mutant $\mathrm{p} 53$ gain-of-function by activating CDK6-p53-RS-PIN1-STAT1 signaling pathway. Chem Res Toxicol. 2020;33: 2361-73.

36 Rai RK. NAT2 and hepatocellular carcinoma: bioinformatic analysis. eLifePress. 2020;1: 11-8.

37 Meng Z, Wu J, Liu X, Zhou W, Ni M, Liu S, et al. Identification of potential hub genes associated with the pathogenesis and prognosis of hepatocellular carcinoma via integrated bioinformatics analysis. J Int Med Res. 2020;48: 300060520910019 .

38 Agarwal R. Smoking, oxidative stress and inflammation: impact on resting energy expenditure in diabetic nephropathy. BMC Nephrol. 2005;6:13.

39 Altamirano J, Bataller R. Cigarette smoking and chronic liver diseases. Gut. 2010;59: 1159-62.

40 Sobin LH, Wittekind $\mathrm{CH}$. Urological tumours. In: Sobin $\mathrm{LH}$, Wittekind $\mathrm{CH}$, editors. TNM classification of malignant tumours. 6th ed. New York, NY: Wiley-Liss; 2002. p. 199-202.

41 Flaman JM, Frebourg T, Moreau V, Charbonnier F, Martin C, Chappuis P, et al. A simple p53 functional assay for screening cell lines, blood, and tumors. Proc Natl Acad Sci U S A. 1995;92:3963-7.
42 Lehmann-Che J, André F, Desmedt C, Mazouni C, Giacchetti S, Turpin E, et al. Cyclophosphamide dose intensification may circumvent anthracycline resistance of p53 mutant breast cancers. Oncologist. 2010;15: 246-52.

43 Schmitz PIM. Statistical methods in cancer research. In: The analysis of case-control studies. Lyon, France: IARC; 2001. Vol. 1.

44 Petitjean A, Mathe E, Kato S, Ishioka C, Tavtigian SV, Hainaut $P$, et al. Impact of mutant p53 functional properties on TP53 mutation patterns and tumor phenotype: lessons from recent developments in the IARC TP53 database. Hum Mutat. 2007;28: 622-9.

45 Cho Y, Gorina S, Jeffrey PD, Pavletich NP. Crystal structure of a p53 tumor suppressorDNA complex: understanding tumorigenic mutations. Science. 1994;265:346-55.

46 Meinhold-Heerlein I, Ninci E, Ikenberg H, Brandstetter T, Ihling C, Schwenk I, et al. Evaluation of methods to detect p53 mutations in ovarian cancer. Oncology. 2001;60: $176-88$.

47 Watanabe J, Nishiyama H, Okubo K, Takahashi T, Toda Y, Habuchi T, et al. Clinical evaluation of $\mathrm{p} 53$ mutations in urothelial carcinoma by IHC and FASAY. Urology. 2004; 63:989-93.

48 Chappuis PO, Estreicher A, Dieterich B, Bonnefoi H, Otter M, Sappino AP, et al. Prognostic significance of p53 mutation in breast cancer: frequent detection of non-missense mutations by yeast functional assay. Int J Cancer. 1999;84:587-93.

49 deVerre White RW, Deitch AD, Gumerlock $\mathrm{PH}$, Shi XB. Use of a yeast assay to detect functional alterations in $\mathrm{p} 53$ in prostate cancer: review and future directions. Prostate. 1999;41: 134-42.

50 Wang $\mathrm{H}$, Liao P, Zeng SX, Lu H. It takes a team: a gain-of-function story of p53-R249S. J Mol Cell Biol. 2019;11:277-83.

51 Wong GS, Lee JS, Park YY, Klein-Szanto AJ, Waldron TJ, Cukierman E, et al. Periostin cooperates with mutant p53 to mediate invasion through the induction of STAT1 signaling in the esophageal tumor microenvironment. Oncogenesis. 2013;2:e59.

52 Gelatti U, Covolo L, Talamini R, Tagger A, Barbone F, Martelli C, et al. N-Acetyltransferase-2, glutathione S-transferase M1 and $\mathrm{T} 1$ genetic polymorphisms, cigarette smoking and hepatocellular carcinoma: a casecontrol study. Int J Cancer. 2005; 115: 301-6.

53 La Vecchia C, Negri E, DeCarli A, D’Avanzo B, Franceschi S. Risk factors for hepatocellular carcinoma in northern Italy. Int J Cancer. 1988;42:872-6.

54 Szymańska K, Lesi OA, Kirk GD, Sam O, Taniere P, Scoazec JY, et al. Ser-249TP53 mutation in tumour and plasma DNA of hepatocellular carcinoma patients from a high incidence area in the Gambia, West Africa. Int J Cancer. 2004;110:374-9. 
55 Camplejohn RS, Rutherford J. p53 functional assays: detecting p53 mutations in both the germline and in sporadic tumours. Cell Prolif. 2001;34:1-14

56 Paget V, Sichel F, Garon D, Lechevrel M. Aflatoxin B1-induced TP53 mutational pattern in normal human cells using the FASAY (Functional analysis of separated alleles in yeast). Mut Res. 2008;656:5561.

57 Li XS, Wang HF, Shi JY, Wang XY, Liu YF, Li K, et al. Genotoxicity study on nicotine and nicotine-derived nitrosamine by accelerator mass spectrometry. Radiocarbon. 1996;38(2):347-53.

58 Bagnardi V, Blangiardo M, La Vecchia C, Corrao G. A meta-analysis of alcohol drink- ing and cancer risk. Br J Cancer. 2001;85: $1700-5$.

59 Persson EC, Schwartz LM, Park Y, Trabert B, Hollenbeck AR, Graubard BI, et al. Alcohol consumption, folate intake, hepatocellular carcinoma, and liver disease mortality. Cancer Epidemiol Biomarkers Prev. 2013;22: $415-21$ 